ture of the past in this manner. The detail of the theory resolves itself into a question of accounting for the differences in the amount of carbonic acid present, all of which was carefully worked out and described by Dr. Hopkins.

A plan for the federation of all local societies with kindred interests was favorably discussed.

$$
\begin{aligned}
& \text { Philip F. SchneIder, } \\
& \text { Corresponding Secretary. }
\end{aligned}
$$

\section{THE BACONIAN CLUB, STATE UNIVERSITY OF} IOWA.

THE following formal papers have been read during the current year :

'Forestry in Iowa': Assistant Professor B. Shimek.

'The Extent and Significance of Food Adulterations ': Dr. E. W. Rockwood.

'The Geology and Scenery of the Pipestone Region': Professor Samuel Calvin.

'Some Features of the Architecture in Westminster Abbey': Dr. J. G. Gilchrist.

'Jelly Fishes and their Relation to the Hydroid Colony': Professor C. C. Nutting.

'Three Famous Problems in Geometry': Dr. J. V. Westfall.

'A Sketch of the Geology of Canada': Mr. R. D. George.

'The Rôle of Insects in the Spread of Diseases': Dr. W. L. Bierring.

'The Mechanics of a Harp String': Professor Laenas G. Weld.

'Concerning the Scope of University Training':

Professor Launcelot W. Andrews.

'The Psychology of Profanity': Professor G. T. W. Patrick.

'The Lost Art of Wood Engraving': Mr. John Springer.

'Some Features of the Road Problem': Professor A. V. Sims.

'The Inscribed Polygon of Seventeen Sides ': A ssistant Professor Arthur G. Smith.

'The Sympathetic Relation of the Two Eyes': Dr.

F. J. Newberry.

'Measurement by Light Waves': Mr. Charles F. Lorenz.

'The Pecuniary Economy of Foods': Mr. A. M. Goettsch.

'Twentieth Century Protoplasm ': Professor T. H. Macbride.

'The Psychological Theory of Organic Evolution':

Dr. H. Heath Bawden.

'Photographic Optics': Professor A. A. Veblen.

'The Modern Theory of Solution': Dr. Carl von Ende.
'Railroad Construction': Mr. W. D. Weeks.

'The Causes of Blindness in Iowa': Dr. L. W. Dean.

Several of the above papers were original contributions to science and have been or will be published.

Among the voluntary reports that have been given during the year the following deserve mention as first announcements: December 7, Professor C. C. Nutting reported on the discovery of a new method of reproduction among the hydro-medusæ. The hydranth has been seen to proceed from the proboscis of the medusa, by a process of budding. December 14th, Professor A. A. Veblen exhibited a new copying-camera table which is capable of all needed adjustments. January 4th, Dr. J. G. Gilchrist reported upon the successful treatment by trephining of three cases of epilepsy of long standing. February 15th, Professor Launcelot W. Andrews exhibited a model to illustrate the process of electrolysis. The same model illustrates Faraday's law of the decomposition of chemical substances. April 26th, Miss Mabel Williams reported the discovery of 'the areavolume illusion,' according to which any dimension of a surface seems larger than the corresponding line and one face of a volume seems larger than the corresponding plane surface. The speaker has demonstrated that the illusion is due to the presence of the judgment 'there is more of it,' which exerts a subconscious influence in the perception. October 12th, the secretary exhibited a new ergograph, and April 19th, new apparatus employed in the study of the voluntary control of the pitch of the voice in singing and speaking. C. E. SEAsHorE, Secretary.

THE ACADEMY OF SCIENCE OF ST. LOUIS.

AT the meeting of the Academy of Science of St. Louis on the evening of May 6th, twentytwo persons present, Mr. C. F. Baker presented an embryological demonstration, including gross and microscopic specimens, covering the development of the chick during the first fortyeight hours of incubation, intended to illustrate a working course in embryology for high schools.

One person was elected to active membership.

William Trelease, Recording Secretary. 